\title{
Predicting Return to Work in a Heterogeneous Sample of Recently Injured Workers Using the Brief OMPSQ- SF
}

Citation for published version (APA):

Nicholas, M. K., Costa, D. S. J., Linton, S. J., Main, C. J., Shaw, W. S., Pearce, R., Gleeson, M., Pinto, R. Z., Blyth, F. M., McCauley, J. H., Maher, C. G., Smeets, R. J. E. M., \& McGarity, A. (2019). Predicting Return to Work in a Heterogeneous Sample of Recently Injured Workers Using the Brief OMPSQ-SF. Journal of Occupational Rehabilitation, 29(2), 295-302. https://doi.org/10.1007/s10926-018-9784-8

Document status and date:

Published: 01/06/2019

DOI:

10.1007/s10926-018-9784-8

Document Version:

Publisher's PDF, also known as Version of record

\section{Document license:}

Taverne

Please check the document version of this publication:

- A submitted manuscript is the version of the article upon submission and before peer-review. There can be important differences between the submitted version and the official published version of record.

People interested in the research are advised to contact the author for the final version of the publication, or visit the DOI to the publisher's website.

- The final author version and the galley proof are versions of the publication after peer review.

- The final published version features the final layout of the paper including the volume, issue and page numbers.

Link to publication

\footnotetext{
General rights rights.

- You may freely distribute the URL identifying the publication in the public portal. please follow below link for the End User Agreement:

www.umlib.nl/taverne-license

Take down policy

If you believe that this document breaches copyright please contact us at:

repository@maastrichtuniversity.nl

providing details and we will investigate your claim.
}

Copyright and moral rights for the publications made accessible in the public portal are retained by the authors and/or other copyright owners and it is a condition of accessing publications that users recognise and abide by the legal requirements associated with these

- Users may download and print one copy of any publication from the public portal for the purpose of private study or research.

- You may not further distribute the material or use it for any profit-making activity or commercial gain

If the publication is distributed under the terms of Article 25fa of the Dutch Copyright Act, indicated by the "Taverne" license above, 


\title{
Predicting Return to Work in a Heterogeneous Sample of Recently Injured Workers Using the Brief ÖMPSQ-SF
}

\author{
M. K. Nicholas ${ }^{1}$ D · D. S. J. Costa ${ }^{1}$ S. J. Linton ${ }^{2} \cdot$ C. J. Main ${ }^{3} \cdot$ W. S. Shaw ${ }^{4} \cdot$ R. Pearce ${ }^{1} \cdot$ M. Gleeson ${ }^{1} \cdot$ R. Z. Pinto ${ }^{1}$. \\ F. M. Blyth ${ }^{5}$. J. H. McCauley ${ }^{6}$. C. G. Maher ${ }^{7}$. R. J. E. M. Smeets ${ }^{8,9} \cdot$ A. McGarity $^{10}$
}

Published online: 23 May 2018

○) Springer Science+Business Media, LLC, part of Springer Nature 2018

\begin{abstract}
Purpose (1) to examine the ability of the Örebro Musculoskeletal Pain Screening Questionnaire-short version (ÖMPSQ-SF) to predict time to return to pre-injury work duties (PID) following a work-related soft tissue injury (regardless of body location); and (2) to examine the appropriateness of 50/100 as a suitable cut-off score for case identification. Methods Injured workers (IW) from six public hospitals in Sydney, Australia, who had taken medically-sanctioned time off work due to their injury, were recruited by insurance case managers within 5-15 days of their injury. Eligible participants $(\mathrm{N}=213$ in total) were administered the ÖMPSQ-SF over the telephone by the case manager. For objective (1) Cox proportional hazards regression analysis was used to predict days to return to PID using the ÖMPSQ-SF. For objective (2) receiver operator characteristic (ROC) analysis was used to determine the ÖMPSQ-SF total score that optimises sensitivity and specificity in detecting whether or not participants had returned to PID within 2-7 weeks. Results The total ÖMPSQ-SF score significantly predicted number of days to return to PID, such that for every 1-point increase in the total ÖMPSQ-SF score the predicted chance of returning to work reduced by $4 \%$ (i.e., hazard ratio $=0.96$ ), $p<0.001$. Sensitivity and specificity for the ROC analysis comparing ÖMPSQ-SF total score to return to PID within 2-7 weeks suggested 48 as the optimal cut off (sensitivity $=0.65$, specificity $=0.79$ ). Conclusion The results provide strong support for the use of the ÖMPSQ-SF in an applied setting for identifying those IW likely to have delayed RTW when administered within 15 days of the injury. While a score of 48/100 was the optimal cut point for sensitivity and specificity, pragmatically, 50/100 should be acceptable as a cut-off in future studies of this type.
\end{abstract}

Keywords Screening $\cdot$ Psychosocial factors · Worker's compensation · Work injury

M. K. Nicholas

michael.nicholas@sydney.edu.au

$1 \quad$ Sydney Medical School - Northern, University of Sydney \& Royal North Shore Hospital, St Leonards, NSW, Australia

2 Department of Law, Psychology, and Social Work, Center for Health and Medical Psychology, Örebro University, Örebro, Sweden

3 Arthritis Care UK Primary Care Centre, Keele University, North Staffordshire, UK

4 University of Connecticut Health Center, Farmington, CT, USA

5 School of Public Health, Concord Clinical School, University of Sydney, Sydney, NSW, Australia
6 Neuroscience Research Australia and School of Medical Sciences, University of NSW, Sydney, NSW, Australia

7 The George Institute, Sydney Medical School, University of Sydney, Sydney, Australia

8 Knowledge Centre Rehabilitation Foundation Limburg, Hoensbroek, The Netherlands

9 Department of Rehabilitation Medicine, Caphri, Maastricht University, Maastricht, The Netherlands

10 Injury Management, Health \& Safety Branch, NSW Fire and Safety, Sydney, Australia 


\section{Introduction}

Delayed return to work (RTW) following common soft tissue work injuries is associated with the development of persistent health problems, loss of employment and the associated substantial costs for the individuals concerned, as well as their families, employers and communities [1-3]. Specifically, the longer an injured worker is absent from work the lower their chances of ever having a sustainable RTW [4-6]. Accordingly, there is a general interest in identifying those injured workers (IW) at risk of delayed RTW as early as possible if these adverse outcomes are to be avoided. Given the large numbers of cases involved, a screening approach has long been seen as the most efficient option for early identification [7]. However, reliably identifying this at risk group has proved difficult, partly due to the lack of tools that are applicable to the diverse range of work injuries and that can be easily administered in time to influence decisions about interventions.

Measures of injury severity seem unreliable predictors of subsequent disability and delayed to work [8-11]. However, evidence from reviews of prospective studies indicates that several psychological and social/environmental factors are more consistent predictors of delayed recovery and disability associated with persisting back pain and associated disability - the leading type of work-related injury $[12,13]$. Importantly, many of the psychosocial risk factors for poor outcome from LBP (the most studied injury site), such as anxiety, depression, catastrophizing, workplace problems, are potentially modifiable and, with appropriate intervention, may reduce the likelihood of long-term disability [14].

One of the critical issues related to screening is the reliable and valid measurement of these psychosocial risk factors. In the main, these risk factors have been assessed in people with recent-onset low back pain only through the use of brief self-report questionnaires in research studies (e.g. $[15,16])$. Few studies have addressed implementation of screening on a larger scale with a wide range of injury sites, especially in the context of a work-injury insurance scheme.

One widely-used self-report scale is the STarT Back Tool [15], but despite its impressive psychometric properties and its acceptability for primary care use this 9-item measure is limited by its focus on back pain only. In addition, it includes no work-related factors, which makes its application for other types of work-related injuries unclear. Another psychosocial screening tool that has also been widely used in primary care research is the Örebro Musculoskeletal Pain Screening Questionnaire (ÖMPSQ) [16]. The ÖMPSQ is not limited to back pain and it contains work-related items, making it potentially more suitable for the typically diverse range of work-related injuries. The ÖMPSQ's psychometric properties have been confirmed by other researchers $[17,18]$. One criticism of the ÖMPSQ has been its length-with 24 items it represents more of a challenge for clinical administration than the 9-item STarT Back. However, Linton et al. [19] reported a shortened, 10-item version of the ÖMPSQ (the ÖMPSQSF). With the short form a cut-off score of 50/100 was found to provide optimal sensitivity (detecting those likely to have more lost time) and specificity (detecting those likely to have less lost time) for identifying individuals with back pain who subsequently had $>2$ weeks off work in the following year. As that study was limited to Swedish workers with back pain, and the screening was done in person, there is still a need to evaluate the ÖMPSQ-SF with recently IW with a range of soft tissue injuries and in another country with a different injury insurance system, and a different mode of administration.

This study had two objectives: (1) to examine the ability of the ÖMPSQ-SF to predict time to return to pre-injury work duties following a work-related soft tissue injury (regardless of body location); and (2) to examine the appropriateness of 50/100 as a suitable cut-off score as a convenient guide to case identification, as identified by Linton et al. [19]. Importantly, in order to evaluate its applicability to the workplace setting, the current study used the ÖMPSQSF in a sometimes adversarial workers compensation system where it was administered by insurance case managers, rather than by independent researchers, and over the phone, rather than face-to-face, to test its fitness for the current practice of the insurance claims team.

\section{Methods}

\section{Participants and Sites}

Study participants were drawn from a larger study comparing a risk-based management protocol with usual practice. This study is based on the sample in the control (usual care) group. In both groups participants were recruited from consecutive injured health workers within 5-15 days of filing a workers compensation claim for a work-related soft tissue injury where surgery was not indicated. Eligible participants had to have taken time off work due to their injury and this had to be sanctioned by their medical doctor. The participants for the full study were obtained from 17 selected public hospitals in the Sydney region of Australia (6 hospitals were designated as 'control' and 11 as 'Intervention sites'). Participants provided informed consent to participate in the screening process for the study after having the purpose of the study explained by the insurance case manager over the telephone. Once consent for screening was achieved, the 
prospective participants were administered the ÖMPSQshort form [19] by telephone. The insurance case managers had been divided into two comparable teams by their senior management: one for the Intervention hospitals and the other for the Control hospitals, in preparation for a controlled trial of early identification and intervention for IW with high psychosocial risk factors for delayed recovery. The case managers (from both teams) administering the screening measure then passed the completed (unscored) scale to the Research Manager (RZP and MG) for scoring. Once the risk status of an IW was determined by the Research Manager, only the Intervention hospital case management team was informed that the IW was high risk. In contrast, the insurance team for the Control hospitals remained blinded to the risk status of the IWs at those hospitals. Those workers scoring 50 or more out of 100 were designated as being at high risk of delayed recovery. If they were working at one of the designated Intervention hospitals, they were asked to meet with their hospital's Return to Work Coordinator (RTWC) within a few days to discuss what the study involved. After that interview, if they wished to participate in phase 2 of the study, they were then referred to a selected psychologist as a follow-up to the screening. The psychologists were asked to utilise the items scored high in the screening tool in their assessment and to determine if the identified problems could be modified by their treatment within six sessions. But those high-risk workers from the designated Control hospitals (who provided the data for this paper) were not referred to a psychologist and continued with their normal care under the NSW Workers Compensation system. Recruitment took place between October 2013 and June 2015.

For the objectives of this study, which was not evaluating the intervention protocol, only those participants from the Control hospitals were used as their scores (and psychosocial risk status) were unknown to the insurance claims team, the workplace, and their treatment providers. The time taken (in days) to return to pre-injury duties (PID) over the following 12 months or longer, was used as the dependent variable. Demographic data and injury data were obtained from the insurance company's records on each injured worker.

\section{Inclusion Criteria}

Participants in the study were health care workers from participating hospitals who reported soft tissue injuries (between October 2013 and June 2015) that were accepted (by the insurer) as work-related, made a claim for workers compensation insurance coverage, and had their injury confirmed by their Nominated Treating Doctor (NTD). They were eligible to participate if the NTD entered an eligible
Table 1 Recorded injury-related diagnoses

\begin{tabular}{lll}
\hline & $\mathrm{N}$ & $(\%)$ \\
\hline Back pain, lumbago, and sciatica & 5 & 3.1 \\
Bursitis & 1 & 0.6 \\
Contusion, bruising and superficial crushing & 11 & 6.7 \\
Disc displacement, prolapse, degeneration or hernia & 2 & 1.2 \\
Dislocation & 2 & 1.2 \\
Epicondylitis & 1 & 0.6 \\
Fracture of vertebral column without mention of spinal cord lesion & 0.6 \\
Ganglion, trigger finger, dupuytren contracture & 1 & 0.6 \\
Multiple injuries & 1 & 1.2 \\
Muscle/tendon strain (non-traumatic) & 2 & 0.6 \\
Neck pain, cervicalgia & 1 & 0.6 \\
Other fractures, not elsewhere classified & 1 & 0.6 \\
Soft tissue injuries due to trauma or unknown mechanisms with insufficient infor- \\
mation to code elsewhere & 32 & 19.6 \\
Tendinitis & & \\
Trauma to joints and ligaments, not elsewhere classified & 1 & 0.6 \\
Trauma to joints and ligaments, unspecified & 6 & 3.7 \\
Trauma to muscles & 23 & 14.1 \\
Trauma to muscles and tendons, not elsewhere classified & 38.7 \\
Trauma to muscles and tendons, unspecified & 63 & 1.8 \\
Traumatic tearing away part of the muscle/tendon structure, avulsion & 3 & 0.6 \\
Unspecified injuries & 1 & 0.6 \\
Total & 1 & 2.5 \\
\hline
\end{tabular}

Data obtained from medical reports for each injured worker 
(physical) diagnosis (see Table 1), and the worker took (medically-sanctioned) time off work due to their injury. In addition, all participants were required to be able to read and speak English well enough to not require an interpreter. All participants in the control arm of the study provided verbal informed consent to participate prior to the telephone screening.

\section{Exclusion Criteria}

Prospective participants were excluded if they had made a stress (or psychological injury) claim, had had no time off work, or had been assessed by their NTD as requiring surgical intervention.

\section{Ethics Approval}

The study was approved by the Sydney Local Health District Human Research Ethics Committee at Concord Hospital (17/06/2013), and the Human Research Ethics Committees of each participating hospital. The study was registered with the Australian and New Zealand Clinical Trials Registry (\# ACTRN12613000847718). The system regulator, WorkCover (NSW), also gave its written approval for the protocol employed in the study. The Senior Management at both NSW Ministry of Health (the employer) and EML Insurance (the insurance agent for that employer), and the underwriter of the NSW workers compensation system (icare) also gave their support, both financially (in the form of a research grant) and by contributing members to a steering committee to provide key stakeholder organizational support in the coordination of the project. The CEOs, General Managers, and Risk Managers for each of the Intervention Hospitals also gave their support for participating in the project.

\section{Measures}

\section{Screening Measure}

The Örebro Musculoskeletal Pain Screening Questionnaireshort form (ÖMPSQ-SF); Linton et al. [19] contains 10 items, each scored on a scale from 0 to 10 , to yield a possible score between 0 and 100. Based on the criteria reported by Linton et al. [19] if a worker scored $\geq 50$ (out of 100) on the screening tool they were considered at high-risk of delayed recovery. Unlike other psychosocial measures that assess a single unified construct, the ÖMPSQ-SF was developed as a cumulative checklist of possible psychosocial factors believed to impact functional recovery. These include pain severity, interference in activities, distress (anxiety and depression), expectations of recovery, and pain-avoidance beliefs.

\section{Outcome Measure}

Lost time from work (days to return to PID). These data were obtained from the insurance company records and accurately reflect the days they paid for the lost time period. Self-report data were not used for this variable.

\section{Statistical Analysis}

The demographic characteristics of the sample were described using means and ranges for several dimensions. We used two approaches to examine the association between ÖMPSQ-SF scores and number of days to return to PID. The first approach involved using Cox proportional hazards regression analysis to predict days to return to PID using the ÖMPSQ-SF. We ran several models, each with a different single predictor: (1) the ÖMPSQ-SF total score; (2) a binary variable representing high (ÖMPSQ-SF total score $\geq 50$ ) or low (ÖMPSQ-SF total score <50) risk; and (3) scores for each of the 10 individual items of the ÖMPSQ-SF. We also used the Hochberg method [20] to control the Type I error rate over these 12 regression analyses. We analysed these models with the single OMPSQ predictor only, and also controlling for age, sex, and the interaction between sex and OMPSQ variable, the latter in order to determine if the association between OMPSQ and days to PID depended on sex.

In the second approach we used receiver operator characteristic (ROC) analysis to determine the ÖMPSQ-SF total score that optimises sensitivity and specificity in detecting whether participants returned to PID. Because ROC requires a binary criterion variable, we classified participants as having either returned to PID within 2 weeks or not. We used both Youden's statistics and a distance statistic to determine optimal sensitivity and specificity [21, 22]. We then repeated this analysis with the same classification, but based on 3,4, 5,6 , or 7 weeks, to determine how consistent the optimal cut off was across time periods. All analyses were conducted in SPSS v24 (SPSS, Inc).

\section{Results}

\section{Sample Characteristics}

In total, of 1655 claims made in the study period, of which $829(50 \%)$ met inclusion criteria. Within this group of 829 , $172(20.7 \%)$ were uncontactable in the time frame for the study and 77 (9\%) refused screening (as participation was voluntary), leaving 580 (70\%). Of these, 213 were in the 'Control' sample. These numbers were further reduced as 3 did not provide usable ÖMPSQ-SF data, 16 were excluded because they underwent surgery, and 31 were excluded because they recorded 0 days off (they were at work, but on 
modified or suitable duties and not PID). This left a sample size for analysis of 163 . Of these, $51 \%$ were screened within 5 days of their injury ( $81 \%$ within 15 days). The mean age was 42.50 (range $20-73, \mathrm{SD}=12.72$ ) and $125(79.1 \%$ ) of the sample were female, which is consistent with the hospital workforce overall. Occupational categories were broad, and included registered nurses, security staff, orderlies, technicians, managers, administrative staff, and paramedics. As can be seen in Fig. 1, about a third of cases reported back pain as their primary injury site, and in Table 1 it can be seen that there were multiple causes of injury (data obtained by the insurance company from the patient's treating doctor).

\section{ÖMPSQ-SF Scores}

The distribution of the ÖMPSQ-SF scores, shown in Fig. 2, can be seen to be approximately normal, ranging from 15 to $95 / 100$, which would also suggest that it is appropriate to use as an outcome measure.

\section{Time to Return to Pre-injury Duties (PID)}

Overall, the data was consistent with the typical pattern of RTW times after disabling injuries, with most returning within a week or so and a small proportion taking much longer than most to RTW (PID).

For the Control sample $(n=163)$ as a whole (including both high and low-risk cases) the median time to return to PID was 13.0 days (range 0.4-725.0; interquartile range 26.71). This time includes the initial (pre-screening) lost days.

High-risk cases (i.e., ÖMPSQ-SF score $\geq 50$ ) had significantly more lost work days (median: 26.6, range 1.1-725.0; interquartile range 45.7) than low-risk respondents (median: 10.1, range 0.6-177.6; interquartile range 19.4), Mann-Whitney $U=2010.5, p<0.001$.

\section{Prediction of RTW Using Cox Regression}

The total ÖMPSQ-SF score significantly predicted number of days to return to PID, such that for every 1-point

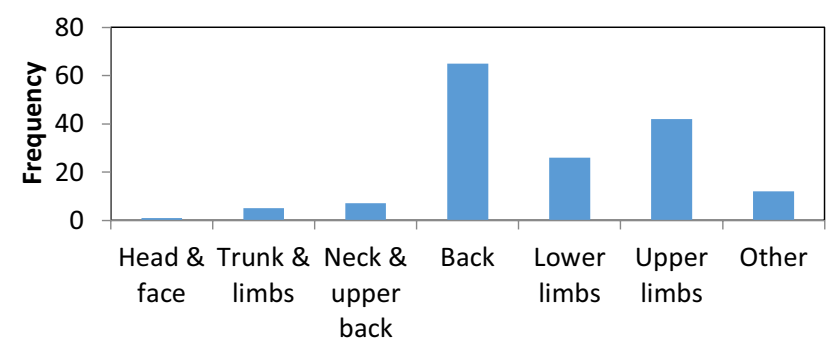

Fig. 1 Distribution of primary injury sites

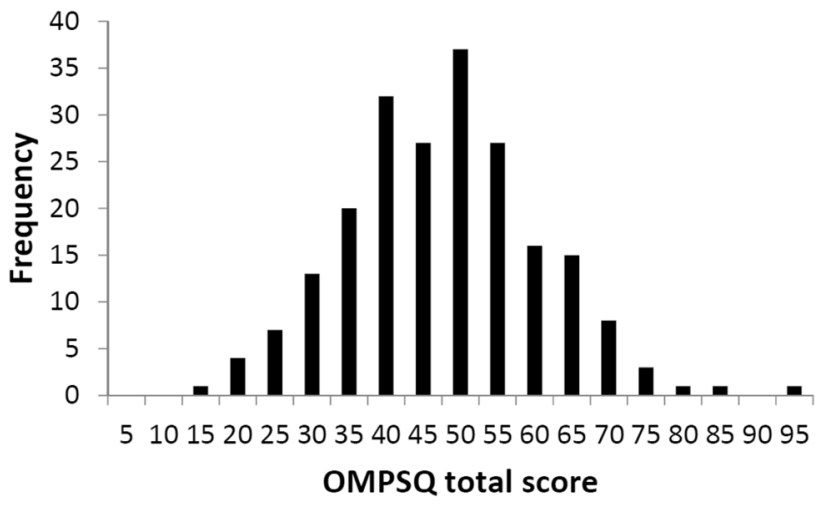

Fig. 2 Distribution of ÖMPSQ-SF scores $(n=163)$

increase in the total ÖMPSQ-SF score the predicted chance of returning to work reduced by $4 \%$ (i.e., hazard ratio 0.96$), p<0.001$. The results of the Cox regression analyses using individual items as predictors are shown in Table 2. In summary, using the Hochberg method [20], which controls for Type I errors, items that significantly predicted days to PID were: 2, 3, 4, 5, 6, 7 and 8 .

Age, sex, and the sex-OMPSQ interaction were not significant predictors, and the changes to estimated effects for each of the OMPSQ predictor variables when these variables were included were negligible.

Table 2 Results of Cox regression analyses predicting number of days to return to PID using the ÖMPSQ-SF

\begin{tabular}{llllll}
\hline Predictor (and item summary) & $\mathrm{HR}^{\mathrm{a}}$ & $\mathrm{P}$ & Mean & $\mathrm{SD}$ & Range \\
\hline Total score & 0.96 & $<0.001^{*}$ & 46.0 & 13.1 & $16-91$ \\
High versus low risk & 0.50 & $<0.001^{*}$ & & & \\
Item 1 (days in pain) & 0.88 & 0.017 & 2.35 & 1.57 & $1-10$ \\
Item 2 (pain severity) & 0.89 & $0.001^{*}$ & 5.80 & 2.29 & $1-10$ \\
Item 3 (limited to light work) & 1.14 & $<0.001^{*}$ & 5.77 & 3.00 & $0-10$ \\
Item 4 (sleep disturbance) & 1.14 & $<0.001^{*}$ & 5.99 & 2.81 & $0-10$ \\
Item 5 (anxiety/tension) & 0.93 & $0.006^{*}$ & 4.98 & 2.77 & $0-10$ \\
Item 6 (feeling depressed) & 0.92 & $0.001^{*}$ & 3.36 & 3.09 & $0-10$ \\
Item 7 (expecting persisting & 0.92 & $0.002^{*}$ & 4.29 & 2.80 & $0-10$ \\
$\quad$ pain) & & & & & \\
Item 8 (lower RTW expec- & 1.20 & $<0.001^{*}$ & 8.88 & 1.89 & $0-10$ \\
$\quad$ tancy) & & & & & \\
Item 9 (stop when pain worse) & 0.99 & 0.716 & 8.85 & 2.15 & $0-10$ \\
Item 10 (avoid work in pain) & 0.96 & 0.078 & 7.02 & 3.44 & $0-10$ \\
\hline
\end{tabular}

*Denotes statistically significant result using the Hochberg correction

${ }^{\dagger}$ Items where a higher score indicates a more positive outcome. For all other items a higher score indicates a worse outcome

${ }^{\text {a }}$ The hazard ratio (HR) is calculated as the exponent of the regression parameter estimate and interpreted as the predicted change in probability of return to work as the predictor increases by 1 


\section{ROC Analysis}

Sensitivity and specificity for the ROC analysis comparing ÖMPSQ-SF total score to return to PID within 2 weeks are summarised in Fig. 3. Both Youden's and the distance statistics suggested 48 as the optimal cut off (sensitivity $=0.64$, specificity $=0.78$, positive predictive value $=0.74$, negative predictive value $=0.69$, area under curve $=0.76$ ) .

The results for the dichotomous return to PID based on work absences of 3 through 7 weeks were similar to those for 2 weeks. The optimal cut off according to the distance statistics was 48 for all time points. Youden's statistic had two peaks for 2 through 5 weeks, at scores of 40 and 48 . Youden's statistic was slightly higher for 40 than for 48 , but because 40 produced relatively low specificity (around 50\% for all cases), we concluded that 48 was a more appropriate cut off. For 6 and 7 weeks, the optimal cut off according to Youden's statistic was 48 .

\section{Discussion}

The present study examined the ability of the 10 -item ÖMPSQ-SF to predict time for RTW (to PID) following a work-related soft tissue injury that had resulted in lost time from work, as well as the appropriateness of 50/100 as a suitable cut-off score for identifying high vs low-risk cases in this context. Importantly, the screening was conducted by each IW's insurance claims manager over the telephone as consideration of the utility of the screening tool included its ability to be administered in a normal

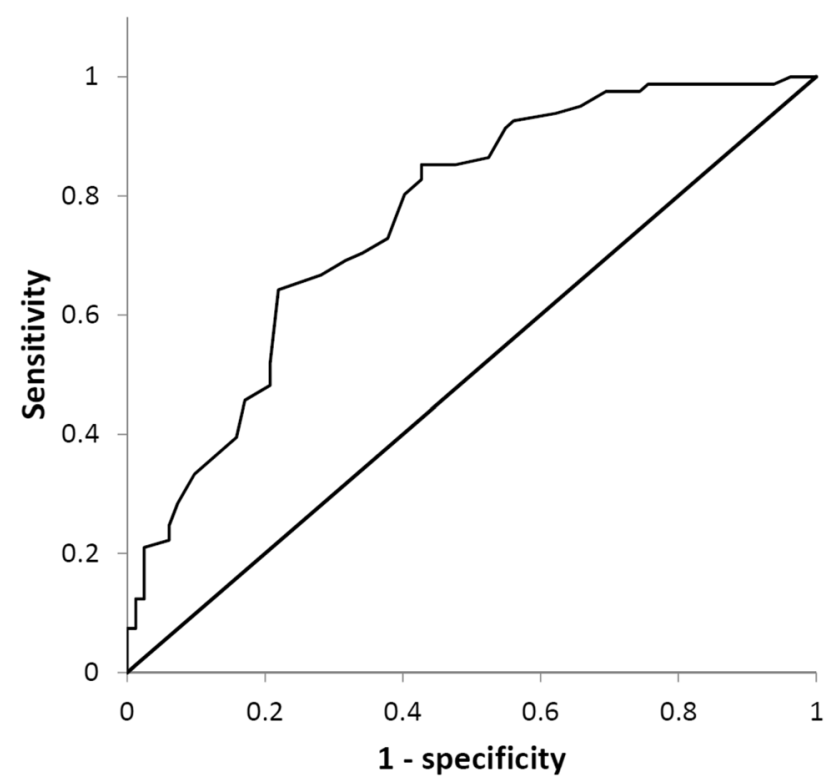

Fig. 3 Sensitivity, specificity for the ROC analysis comparing ÖMPSQ-SF total score to return to PID within 2 weeks insurance claims context. The study recruited a final sample of 163 IW with injuries at different sites, $81 \%$ within 15 days of their injury. 75 (46.0\%) of these workers were identified as being in the high-risk category based on the criterion of 50/100 on their ÖMPSQ-SF scores. Data provided by the workers compensation insurer indicated that for the sample as a whole, the median number of days to return to PID at work was 13.0 days. For participants with an ÖMPSQ-SF score $\geq 50 / 100$ (the high risk group) the median time to RTW was 26.6 days versus 10.1 days for the low-risk participants. It should be kept in mind that in this study if an IW submitted a work injury claim, but did not lose time from work s/he was not included in the study.

Overall, these results provide strong support for the use of the ÖMPSQ-SF in an applied setting for identifying those IW likely to have delayed RTW when administered within 15 days of the injury. In addition, the ROC analysis comparing ÖMPSQ-SF total scores to return to PID within 2 weeks revealed a score of 48/100 was the optimal cut point for sensitivity and specificity. This score provided the best balance between false positives (misclassifying IWs as high risk) and false negatives (misclassifying IWs as low risk). The same score was also the best fit for predicting 3-7 weeks off work. This finding closely corroborates the cut-off reported by Linton et al. [19] of 50/100 that was used in the present study. Accordingly, and from a pragmatic perspective, and consistent with Linton et al. [19], it would seem that 50/100 should be acceptable as a cut-off in future studies of this type.

The finding from the Cox regression analyses that total ÖMPSQ-SF score predicted the number of days to return to PID, such that for every 1-point increase in the total ÖMPSQ-SF score the predicted chance of returning to work reduced by $4 \%$, provides further reason to employ the tool as part of an early screening process. The results of the Cox regression analyses using individual items as predictors indicated that scores on items 2, 3, 4, 5, 6, 7 and 8 were significant. These findings suggest that a 7 -item version of the ÖMPSQ-SF could be considered. However, not only would this require replication of this finding in another sample first, it may be considered unnecessary as the other three items could still be of interest to researchers and clinicians anyway. Examination of the significant items reveals several consistencies with previous research on predictors of outcomes following work injuries. Specifically, higher pain severity (Item 2), perceived activity limitations (Item 3), and the associated sleep interference (Item 4), as well as heightened anxiety (Item 5) and depression (Item 6) have repeatedly been found to predict future disability following onset of pain [13, 23, 24]. Low recovery expectations (Items 7 and 8 ) have also been found by others to be predictive of worse functional outcomes, including delayed RTW [25]. 
The finding that the two 'fear-avoidance' (or behavioural items), specifically, \#9: An increase in pain is an indication that I should stop what I' $m$ doing until the pain decreases, and \#10: I should not do my normal work duties with my present pain, were not predictive of time to return to preinjury work duties is interesting and consistent with some, but not all, other findings on future disability levels [26]. This suggests the role of fear-avoidance beliefs in predicting time off work after an injury may need to be reviewed. In this study all respondents reported a moderate degree of pain (mean: 5.84/10; SD 2.26) and the severity of pain was found to be predictive of work absence. It is also true that pain behaviours of this type have been shown consistently to be predictive of chronic pain-associated disability [27], but that may suggest a difference between disability (interference in activities) is not automatically synonymous with time to return to full work duties. It is known, for example that many IW do RTW despite their persisting injuries and associated pain, suggesting that other factors should also be taken into consideration when predicting RTW following an injury [24, 28]. The distinction between RTW and disability may be the important issue here.

We found no effects of sex (or its interaction) on the association of the ÖMPSQ-SF with RTW. Though males and females frequently show differences in musculoskeletal pain and disability outcomes, sex did not appear to affect the validity of the ÖMPSQ-SF as a predictor of RTW in this working cohort. As job demands, industry mix, and occupation types tend to vary between males and females as a group, this variable should continue to be considered a logical covariate and included in psychometric analyses with the ÖMPSQ-SF in future studies.

It may also be important to consider that other studies appear to have examined fear-avoidance beliefs (and behaviours) somewhat later than was done in the present study. A systematic review by Wertli et al. [28] found that fear-avoidance beliefs were less prognostic when assessed earlier than 2 weeks after injury (as for most in the present study) and $>3$ months after pain onset. Our data may be a consequence of the role of the individual predictors at different stages in the development of disability; the presence of symptoms and specific beliefs may lead to the development of pain-related fear and avoidance at a later stage (prior to the development of chronic disability and work loss).

It might be hypothesised further that the strength of predictors, and associated prognostic tools may change with the passage of time in accordance with the mechanisms underlying the development of chronic disability; the relative strengths of the different types of predictor may be affected significantly by the time span post-injury at which the predictors are investigated; and pain disability models may be more dynamic and reactive than is sometimes supposed.
However addition data is clearly required to further investigate these hypotheses (see [7]).

In relation to other studies that have evaluated the predictive value of the ÖMPSQ, or other psychosocial risk factor tools, a notable feature and strength of this study was its use of an objective outcome measure (insurance company documented RTW) rather than self-reported measures, like perceived disability (e.g. [26]). Comparisons between selfreported outcomes and objective measures, like documented RTW status, have revealed differences in findings, especially in relation to psychosocial risk factors (e.g. [29]).

Other strengths of this study that provide a degree of confidence in interpreting the findings include its prospective design, the use of an adequate number of cases for the analyses conducted, and the use of a sample of IW with heterogeneous injuries/sites. The latter feature, in particular, means the results should be readily generalizable to a broad population of IW. Varying amounts of lost time were examined in relation to the sensitivity/specificity of the optimal cut-point and this remained the same for the periods examined (2-7 weeks). In addition, the telephone administration of the screening was successfully integrated into the normal practice of the insurance case managers, as opposed to relying on external (and temporary) researchers, and this provides some confidence for the utility of the screening methodology in normal work injury management.

The limitations of the study should also be acknowledged and these include the lack of inclusion of other measures or variables that could also be useful in predicting lost time from work. These could have included measures of mood, prior health status, prior sickness absence, work satisfaction, marital status, education levels, and workplace factors, such as the nature of the work, level of job control, and relationships with supervisors, etc. [11, 24]. However, the present study was intended to test the value of the ÖMPSQ-SF as a simple screening measure for identifying those IW at risk of delayed RTW rather than considering all potential predictors of this outcome. This provided an efficient means of selecting those workers likely to require closer assessment of these and other possible psychosocial risk factors which can be done in person.

The logical next step following the findings reported here is to determine if high risk IW identified in the manner described here would have earlier RTW outcomes if the psychosocial risk factors signalled by their ÖMPSQ-SF score were addressed. The literature review by Nicholas et al. [14] reported evidence to support this conclusion in people with sub-acute low back pain, but it has not been demonstrated in a broader and more heterogeneous injured worker sample in a compensable environment. This is a considerably more complex task than simply completing a screening tool, and it requires researchers to consider multiple factors and multiple 
levels of influence quite apart from a specific treatment [30]. This will be addressed in a later stage of the larger project.

Acknowledgements This study was supported by a grant from the NSW Ministry of Health, EML Insurance, and SI-CORP (now icare). We would like to specifically acknowledge the contributions to the study by Karen Munk, Tamara Sprod, Rachel Elmes, Claims managers and staff at EML; Robert Lloyd, Susan Rafty, and Steven Hunt at icare; Michele Murphy and John Roach from NSWHealth; Dr Rob Boland, Discipline of Physiotherapy, Faculty of Health Sciences, University of Sydney; and the CEO's, General Managers, and RTW coordinators at each participating hospital.

Funding This study was supported by a grant from the NSW Ministry of Health, EML Insurance, and SI-CORP (now icare). The grant funding supported only the work performed by the two project managers (Michael Gleeson, and Raphael Z Pinto).

\section{Compliance with Ethical Standards}

Conflict of interest The authors declare that they have no conflict of interest.

Ethical Approval The study was approved by the Sydney Local Health District Human Research Ethics Committee at Concord Hospital (17/06/2013), and the Human Research Ethics Committees of each participating hospital. The study was registered with the Australian and New Zealand Clinical Trials Registry (\# ACTRN12613000847718). The system regulator, WorkCover (NSW), also gave its written approval for the protocol employed in the study.

Informed Consent Informed consent was obtained from each injured worker by telephone during the initial discussion between the injured workers and the insurance case managers.

\section{References}

1. Goetzel RZ, Long SR, Ozminkowski RJ, Hawkins K, Wang S, Lynch W. Health, absence, disability, and presenteeism cost estimates of certain physical and mental health conditions affecting U.S. employers. J Occup Environ Med. 2004;46(4):398-412.

2. Peterson CL, Murphy G. Transition from the labor market: older workers and retirement. Int J Health Serv. 2010;40(4):609-627.

3. Schofield DJ, Shrestha RN, Percival R, Callander EJ, Kelly SJ, Passey ME. Early retirement and the financial assets of individuals with back problems. Eur Spine J. 2011;20(5):731-736.

4. Johnson D, Fry T. Factors affecting return to work after injury: a study for the Victorian WorkCover Authority. Melbourne: Melbourne Institute of Applied Economic and Social Research; 2002.

5. Landstad BJ, Wendelborg C, Hedlund M. Factors explaining return to work for long-term sick workers in Norway. Disabil Rehabil. 2009;31(15):1215-1226.

6. Wynne-Jones G, Cowen J, Lordan JL, Uthman O, Main CJ, Glozier $\mathrm{N}$, et al. Absence from work and return to work in people with back pain: a systematic review and meta-analysis. Occup Environ Med. 2014;71(6):448-456.

7. Waddell G, Burton AK, Main CJ. Screening of DWP clients for risk of long-term incapacity: a conceptual and scientific review. London: Royal Society of Medicine Press; 2003.

8. Carragee EJ, Alamin TF, Miller JL, Carragee JM. Discographic, MRI and psychosocial determinants of low back pain disability and remission: a prospective study in subjects with benign persistent back pain. Spine J. 2005;5(1):24-35.
9. Hepp U, Moergeli H, Buchi S, Bruchhaus-Steinert H, Sensky T, Schnyder U. The long-term prediction of return to work following serious accidental injuries: a follow up study. BMC Psychiatry. 2011;11(1):53. https://doi.org/10.1186/1471-244X-11-53.

10. Mills R. Predicting failure to return to work. Intern Med J. 2012;42(8):924-927.

11. Street TD, Lacey SJ. A systematic review of studies identifying predictors of poor return to work outcomes following workplace injury. Work 2015;51(2):373-381.

12. Chou R, Shekelle P. Will this patient develop persistent disabling low back pain? J Am Med Assoc. 2010;303(13):1295-1302.

13. Mallen CD, Peat G, Thomas E, Dunn KM, Croft PR. Prognostic factors for musculoskeletal pain in primary care: a systematic review. Br J Gen Pract. 2007;57(541):655-661.

14. Nicholas MK, Linton SJ, Watson PJ, Main CJ. The early identification and management of psychological risk factors (Yellow Flags) in patients with low back pain: a reappraisal. Phys Ther. 2011;91(5):737-753.

15. Hill JC, Dunn K, Lewis M, Mullis R, Main CJ, Foster NE, et al. A primary care back pain screening tool: identifying patient subgroups for initial treatment. Arthritis Care Res. 2008;59(5):632-641.

16. Linton SJ, Boersma K. Early identification of patients at risk of developing a persistent back problem: the predictive validity of the Orebro Musculoskeletal Pain Questionnaire. Clin J Pain. 2003;19(2):80-86.

17. Hockings RL, McAuley JH, Maher CG. A systematic review of the predictive ability of the Örebro Musculoskeletal Pain Questionnaire. Spine. 2008;33(15):E494-E500.

18. Maher CG, Grotle M. Evaluation of the predictive validity of the Orebro Musculoskeletal Pain Screening Questionnaire. Clin J Pain. 2009;25(8):666-670.

19. Linton SJ, Nicholas MK, MacDonald S. Development of a Short Form of the Örebro Musculoskeletal Pain Screening Questionnaire. Spine 2011;36(22):1891-1895.

20. Hochberg Y. A sharper bonferroni procedure for multiple tests of significance. Biometrika 1988;75(4):800-802.

21. Liu X. Classification accuracy and cut point selection. Stat Med. 2012;31(23):2676-2686.

22. Youden WJ. Index for rating diagnostic tests. Cancer 1950;3(1):32-35.

23. Kelly GA, Blake C, Power CK, O'Keeffe D, Fullen BM. The association between chronic low back pain and sleep: a systematic review. Clin J Pain. 2011;27(2):169-181.

24. Lotters F, Burdorf A. Prognostic factors for duration of sickness absence due to musculoskeletal disorders. Clin J Pain. 2006;22(2):212-221.

25. Fadyl J, McPherson K. Return to work after injury: a review of evidence regarding expectations and injury perceptions, and their influence on outcome. J Occup Rehabil. 2008;18(4):362-374.

26. Foster NE, Thomas E, Bishop A, Dunn KM, Main CJ. Distinctiveness of psychological obstacles to recovery in low back pain patients in primary care. Pain 2010;148(3):398-406.

27. Leeuw M, Goossens MEJB., Linton SJ, Crombez G, Boersma K, Vlaeyen JWS. The fear-avoidance model of musculoskeletal pain: state of the scientific evidence. J Behav Med. 2007;30(1):77-94.

28. Wertli MM, Rasmussen-Barr E, Weiser S, Bachmann LM, Brunner $\mathrm{F}$. The role of fear avoidance beliefs as a prognostic factor for outcome in patients with nonspecific low back pain: a systematic review. Spine J. 2014;14(5):816-836.

29. Gauthier N, Sullivan MJL, Adams H, Stanish WD, Thibault P. Investigating risk factors for chronicity: the importance of distinguishing between return-to-work status and self-report measures of disability. J Occup Environ Med. 2006;48(3):312-318.

30. Main CJ, Nicholas MK, Shaw WS, Tetrick LE, Ehrhart MG, Pransky G. Implementation science and employer disability practices: embedding implementation factors in research designs. J Occup Rehabil. 2016;26(4):448-464. 